\title{
The 4th international conference on metrology: measurement and testing in the service of society, 23-24 May 2011, Jerusalem, Israel
}

\author{
Ilya Kuselman
}

Published online: 8 September 2011

(C) Springer-Verlag 2011

We teach students that there are three categories of metrology: (1) scientific (including fundamental metrology), (2) industrial (applied metrology) and (3) legal metrology [1]. Scientific metrology deals with development and maintenance of measurement standards and methods, and serves industrial and legal metrology. In its turn, industrial metrology, applied for calibration of measurement instruments and testing, serves production processes, trade and other fields of human activity for ensuring quality of life. Legal metrology serves legal aspects of economic transactions, fulfilling some laws and ensuring that the measurement effects of the law are acceptable in context, etc.

The recent International Conference on Metrology in Jerusalem 2011 taught us how the international organizations of the three categories of metrology define their strategy and practice in the service of society. The conference was organized by the Israeli Metrological Society and the ISAS International Seminars in cooperation with the National Conference of Standard Laboratories-International (NCSLI), the Cooperation on International Traceability in Analytical Chemistry (CITAC) and the Israel Analytical Chemistry Society [2].

There were two plenary lectures by Dr. Richard Davis, Bureau International des Poids et Mesures (BIPM), France, about the benefits of reduced uncertainties in calibration services for industry and society, and about proposed changes to the international system of units: motivations and consequences. Mr. Steve Sidney, National Laboratory Association, South Africa, reported on NCSLI activity and

I. Kuselman $(\square)$

The National Physical Laboratory of Israel (INPL),

Givat Ram, Jerusalem 91904, Israel

e-mail: ilya.kuselman@moital.gov.il discussed why testing and calibration laboratories should talk to each other. In the field of metrology, in chemistry, two brilliant plenary lectures were delivered. One, by Prof. Frantz Ulberth, European Commission, Joint Research Centre, Institute for Reference Materials and Measurements, Belgium, was on metrological concepts required for food safety and quality testing. In the second one, Prof. Mayer Brezis, Center for Clinical Quality and Safety, Hadassah Hebrew University Medical Center, Israel, talked about the false sense of certainty which arises from the illusion of accuracy and precision in measurements. The plenary lecture 'How legal metrology helps countries succeed in the global marketplace' was delivered by Mr. Alan Johnston, Measurement Canada, President of the International Committee of Legal Metrology. A session and a panel were also dedicated to legal metrology.

CITAC was represented by Mr. Daniel Tholen, Dan Tholen Statistical Consulting, USA, Dr. Chainarong Cherdchu, the National Institute of Metrology, Thailand, and me. Mr. Tholen leaded the preconference workshop 'Interpreting proficiency testing results' and delivered a key-note lecture on the topic during the conference. Dr. Cherdchu presented with his colleagues the quality infrastructure for agricultural products in Thailand. I reported consensus and metrological approaches in proficiency testing of a limited number of participants, and outof-specification test results in stability study of drug products (recent joint projects of the International Union of Pure and Applied Chemistry and CITAC). The main message was that understanding of postulates and concepts of an approach is crucial to avoid confusing results of the approach use and corresponding illusions.

One could hear many interesting things in the conference if listened closely. However, when I listened to a representative of scientific metrology, my strange feeling 
was that scientific metrology only provides decisions on problems arising in measurement and testing, conformity assessment and/or other fields of use of measurement/ analysis/test results. The same accent was present in some lectures on legal metrology and the International Organization of Legal Metrology (OIML) 'paving the way towards a Global Metrology System' [3]: the law usually comes before all. On the other hand, a representative of the International Laboratory Accreditation Cooperation (ILAC) could say that quality assurance achievements in measurement and testing, overcoming trade barriers, etc., are only possible due to laboratory accreditation. Thus, in spite of the collaboration of BIPM, OIML and ILAC, which probably started from the common statement and declaration [4], a mutual recognition of the role of different categories of metrology and of accreditation in their service of society has not been established yet in practice.

Moreover, the basic role of field calibration and testing laboratories-fulfilling routine (and sometimes not routine) tasks of industrial metrology, answering questions dealing with accreditation requirements and other challenges-is not infrequently forgotten. Many practitioner reports from such laboratories were presented on topics of measurement uncertainty in calibration and testing, measurement quality and its effect on decision making, method validation in chemical measurements and validation of calibration methods, etc.

The selected conference presentations are published in this issue.

Ilya Kuselman

Guest Editor, Topical Issue

"Measurement and Testing in the Service of Society"

\section{References}

1. European Association of National Metrology Institutes (2008) Metrology in short, 3rd edn. http://www.euramet.org/index.php? $\mathrm{id}=$ mis

2. The 4th international conference on metrology, 23-24 May 2011, Jerusalem, Israel. http://www.isas.co.il/metrology2011

3. OIML home page, http://www.oiml.com

4. Common statement and declaration by the BIPM, OIML and ILAC on the relevance of various international agreements on metrology to trade, legislation and standardization. http://www.bipm.org/ utils/common/pdf/bipm-oiml-ilac_joint_declaration.pdf 